\title{
ARTICLE
}

\section{A development of optimized radiation shielding design method for contaminated soil in Fukushima}

\author{
Ken-ichi Kimura ${ }^{\text {a,d,e*}}$, Yusuke Suzuki ${ }^{b}$, Takushi Takata ${ }^{c}$, Yusuke Fujikura ${ }^{d}$, Hiroshi Kubota ${ }^{d}$, Yujin Lee ${ }^{\mathrm{e}}$, Sanjay Pareek ${ }^{\mathrm{f}}$ \\ and Yoshikazu Araki b,e \\ ${ }^{a}$ K-Tech, 6-47-14 Syonandai, Fujisawa-shi, Kanagawa-ken, Japan; ${ }^{b}$ Kyoto University, Kyotodaigaku-katsura, nisikyo-ku, Kyoto-shi, \\ Kyoto-fu, 615-8540 Japan; ${ }^{C}$ The Wakasa Wan Energy Research Center, 64-52-1 Hase, Tsuruga-shi, Fukui-ken, 914-0192, Japan; \\ ${ }^{d}$ Fujita Corporation, 2025-1 Ono, Atsugi-shi, Kanagawa-ken, 245-0125, Japan; ${ }^{e}$ Structural Technology Research Association, \\ 37-2 Shimotobahiroosa-cho, Fushimi-ku, Kyoto-shi, Kyoto-fu, 612-8473, Japan; ${ }^{f}$ Nihon University, 1 Nakagawara Tokusada \\ Tamura-cho, Koriyama-shi, Fukushima-ken, 963-8642, Japan
}

\begin{abstract}
In order to solve the situation laying contaminated soils beside children on a daily basis, two types of shielding concrete pods and two levels of the contaminated soil with radioactive cesium were prepared. First concrete pod was made by special heavy concrete with the density of $4.57 \mathrm{~g} / \mathrm{cm}^{3}$, which were developed by using special iron balls and developed mixture tables. Second pod was made by recycled concrete consisted of aggregate from collapsed building in Miyagi with density of $2.13 \mathrm{~g} / \mathrm{cm}^{3}$. Two pods were cylindrical shapes with diameters of $0.5 \mathrm{~m}$ and $0.7 \mathrm{~m}$, and with heights of $0.6 \mathrm{~m}$ and $0.8 \mathrm{~m}$, respectively. These pods can contained 28 liters of contaminated soils (diameter of $0.25 \mathrm{~m}$ and height of $0.4 \mathrm{~m}$ ) and designed same shielding effect in the beginning stage. Dose rates were measured from two sorts of contaminated soil samples with heavy concrete pod, recycled concrete pod, and themselves (without shielding) in Fukushima by the survey meter, which was calibrated by ${ }^{137}$ Cs standard source. On the other hand, Monte Carlo simulations by MCNP4C2 were carried out for two sorts of contained soils and two types of manufactured concrete pods. The simulations gave good agreements with measured results and therefore the accuracy of the simulation was confirmed. So, some investigational optimization calculations were performed.
\end{abstract}

Keywords: concrete shielding pod; heavy concrete; recycle concrete; shielding design; optimized design method; radioactive Cesium; MCNP

\section{Introduction}

Tremendous quantities of radioactive plume were dispersed from Fukushima Daiichi Nuclear Power Plant which fell down to the ground, and large quantities of contaminated materials, such as soil, fallen leaves, and rubble were spread out. In contrast, decontamination is conducted in wide area around the power plant and the amount of removed soil from the contaminated land is growing as a radioactive waste. These contaminated materials should be properly contained and be under the certain control. We, therefore, propose a concrete shielding pod to contain the contaminated materials.

Concrete is the materials which are used for shielding against $\gamma$-ray (including $\mathrm{X}$-ray) and neutron in the nuclear plants and accelerator facilities. With the above situation, a lot of investigations and developments of shielding have been already performed, such as heavy concrete for $\gamma$-ray shielding [1], boron contained

*Corresponding author. Email: ksjkimura@gmail.com materials for neutron shielding [2] and absorption [3], low-activation concrete for reducing radioactive waste [4], and so on.

On the other hand, huge quantities of contaminated materials, which mainly contain ${ }^{134} \mathrm{Cs}$ and ${ }^{137} \mathrm{Cs}$ as radionuclide, have been waiting for proper shielding and containment in the polluted area including Fukushima prefecture. For that situation, a designing method for effective shielding is necessary for solving the problem related to containment of contaminated materials.

In this paper, experimental shielding work against sampled contaminated soils with newly developed two types of concrete pods were described in order to solve the problem above. The experimental data were compared to the simulated results with Monte Carlo method. After the verification of the simulation method by the comparison above, some shielding geometries were also investigated with three kinds of concrete and two levels of contaminated soils, in order to establish the most effective shielding design for the contaminated materials. 


\section{Experiment}

\subsection{Concrete shielding pods}

Two types of concrete were prepared for shielding concrete pods. First one is "Recycled concrete (Rcon)", which consists of recycled aggregate from Miyagi prefecture, crushed sand, water, and ordinary Portland cement. Another is "High density concrete (Hcon)", which have been developed for heavy concrete with density more than $4.5 \mathrm{~g} / \mathrm{cm}^{3}$. Iron grain and powder were used as an aggregate for the concrete, with ordinary Portland cement and water as a binder. For the density, weight percentage of iron aggregate should be $75 \%$ or more from the mixture table estimation. So several trial experiments of concrete mixture with various types of iron materials in shape and size, were conducted to achieve the mixture table for the density.

The shielding concrete pods were planned for the containment of contaminated soils in Fukushima prefecture. Volume of containment part was fixed with the cylindrical shape of $245 \mathrm{~mm}$ in diameter and $400 \mathrm{~mm}$ in height, in order to conclude gross weight of both concrete shielding pods less than 1 ton. Geometry of the concrete shielding pod is shown in Figure $\mathbf{1}$ and its dimensions are given in Table 1.

\subsection{Contaminated soil samples}

Four kinds of contaminated soil were taken as samples in Fukushima prefecture. Four specimens of about $40 \mathrm{~kg}$ each were separated to two groups in the levels of dose rates by portable dose meter, such as "high contaminated soils group (Hsoil)" and "middle contaminated soils group (Lsoil)". Each group of soils was mixed well to be homoginius, and 64 samples with

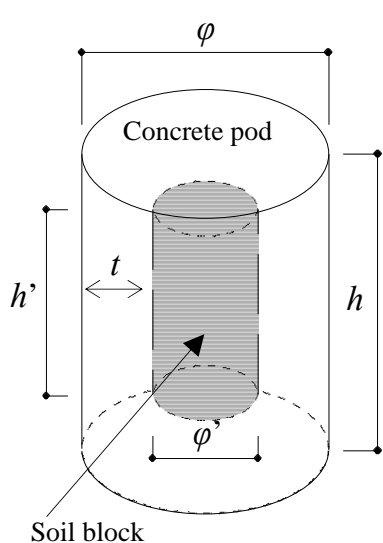

Table1. Sizes of shielding pods.

Figure 1. Shape of the pods.

\begin{tabular}{ccc}
\hline Size & $\begin{array}{c}\text { Recycle } \\
\text { concrete } \\
\text { (Rcon) }\end{array}$ & $\begin{array}{c}\text { High } \\
\text { density } \\
\text { concrete } \\
\text { (Hcon) }\end{array}$ \\
\hline \hline$t$ & 200 & 100 \\
\hline$\varphi$ & 700 & 500 \\
\hline$h$ & 800 & 600 \\
\hline$\varphi^{\prime}$ & \multicolumn{3}{c}{300} \\
\hline$h^{\prime}$ & \multicolumn{3}{c}{400} \\
\hline
\end{tabular}

Unit : mm

Table 2. Detail description of three soil blocks.

\begin{tabular}{|c|c|c|c|c|c|}
\hline \multirow{3}{*}{$\begin{array}{l}\text { Soil } \\
\text { block }\end{array}$} & \multicolumn{2}{|c|}{ Size $(\mathrm{mm})$} & \multirow{2}{*}{\multicolumn{2}{|c|}{ Weight (kg) }} & \multirow{3}{*}{$\begin{array}{c}\text { Total } \\
\text { activity } \\
10^{6} \mathrm{~Bq}\end{array}$} \\
\hline & Diameter & Height & & & \\
\hline & inner outer & inner outer & inne & outer & \\
\hline SB1 & 242 & 400 & 22.4 & & 1.75 \\
\hline SB2 & 186 & 300 & 10.6 & & 0.835 \\
\hline SB3 & 186 & 300 & 10.6 & 14.8 & 1.15 \\
\hline
\end{tabular}

$150 \mathrm{~g}$ were extracted from each group to measure the activities by Ge detector. The average activities of Hsoil for ${ }^{134} \mathrm{Cs}$ and ${ }^{137} \mathrm{Cs}$ on $9^{\text {th }}$ of March, 2012 were 31.2 $\mathrm{Bq} / \mathrm{g}$ and $47.7 \mathrm{~Bq} / \mathrm{g}$, and those of Lsoil were 8.09 and 12.4 Bq/g, respectively.

Three soil blocks were prepared from two soil groups for the experimental measurement. "Soil block 1 (SB1)" and "Soil block 2 (SB2)" were consisted by Hsoil only. "Soil block 3 (SB3)" had two layers with two soil group (Hsoil for the inner layer and Lsoil for the outer layer).

Table 2 shows the detail of soil blocks.

\subsection{Measurement}

Geometry of the measurement is shown in Figure 2. Dose rates were measured for soil blocks only and for those with the two kinds of shielding concrete pods by the survey meter (Survey Instrument Model 5000). Several measurements in each condition were conducted as an integrated value for 3 minute per one measurement. In addition, measurements without contaminated soil blocks were also performed several times, and the relatively high environmental background of 0.6-0.8 $\mu \mathrm{Sv} / \mathrm{h}$ was estimated.

Measurements were conducted for the three soil blocks (SB1, SB2 and SB3) with the two concrete shielding pods (Rcon and Hcon) or without pods (Bare).

\section{Simulation}

The MCNP4C2 [5] code was employed for Monte Carlo simulation of photon in this work using MCPLIB02 photo library [6] with "Radiation dose conversion coefficients for radiation shielding calculations: 2010 [7]”. Isotropic photon sources were uniformly placed in the region of the soil blocks with activities of ${ }^{134} \mathrm{Cs}$ and ${ }^{137} \mathrm{Cs}$ described above. The simulation geometries were made along with the measured conditions, as shown in Figure 2, with the
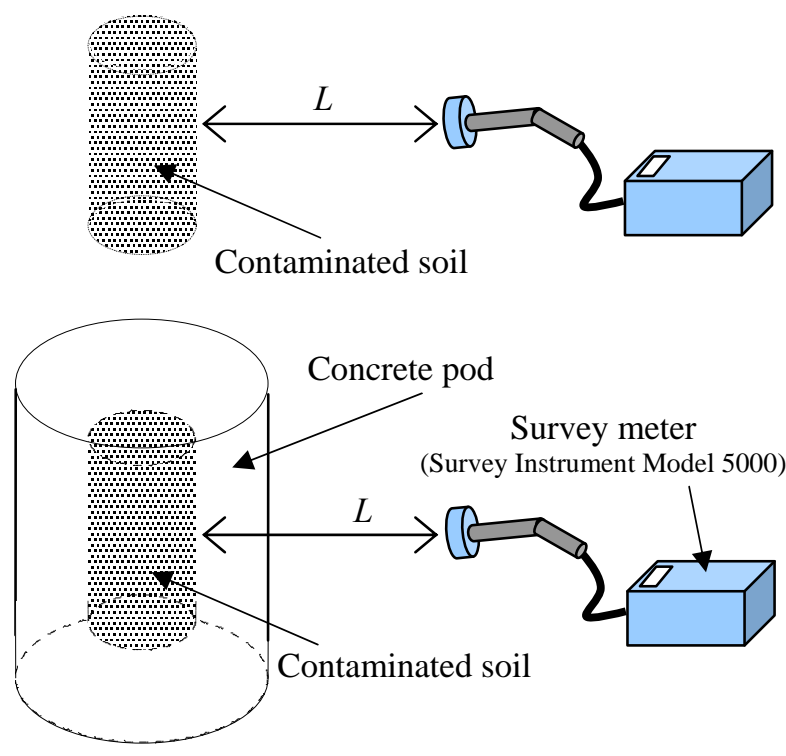

Figure 2. Geometry of measurement. 
cylindrical volume sources (SB1, SB2 and SB3) with and without the shielding pods. In addition to the two pods of Rcon or Hcon, the simulation with a concrete pod of a middle density of $3.09 \mathrm{~g} / \mathrm{cm}^{3}$ (Mcon), which had currently been under developing, was also performed. Mcon consisted of steel slag, ordinary Portland cement and water. Simulations with various shield thickness (t) from 0.1 to $0.6 \mathrm{~m}$ for Rcon, Mcon and Hcon were performed and dose rates were estimated at the outer surfaces and at the distant locations away from those surfaces of the soil blocks (for BARE) and the shielding pods (for Rcon, Mcon and Hcon).

\section{Comparison between measurement and simulation}

Figure 3 shows attenuation curves of dose rates for the two soil blocks (SB1 and SB3) with 3 kinds of concrete shielding pods (Rcon, Mcon and Hcon) as a function of shielding thickness or without pods (BARE) as a function of distance (L) compared between the simulated results (four lines each) and the measurement (five plots each). Table 3 gives ratios of the simulated dose rates to the measured ones $(\mathrm{C} / \mathrm{E})$ at the position of distance $\mathrm{L}$ between cylindrical surfaces of soil blocks and survey meter for three soil blocks without pods
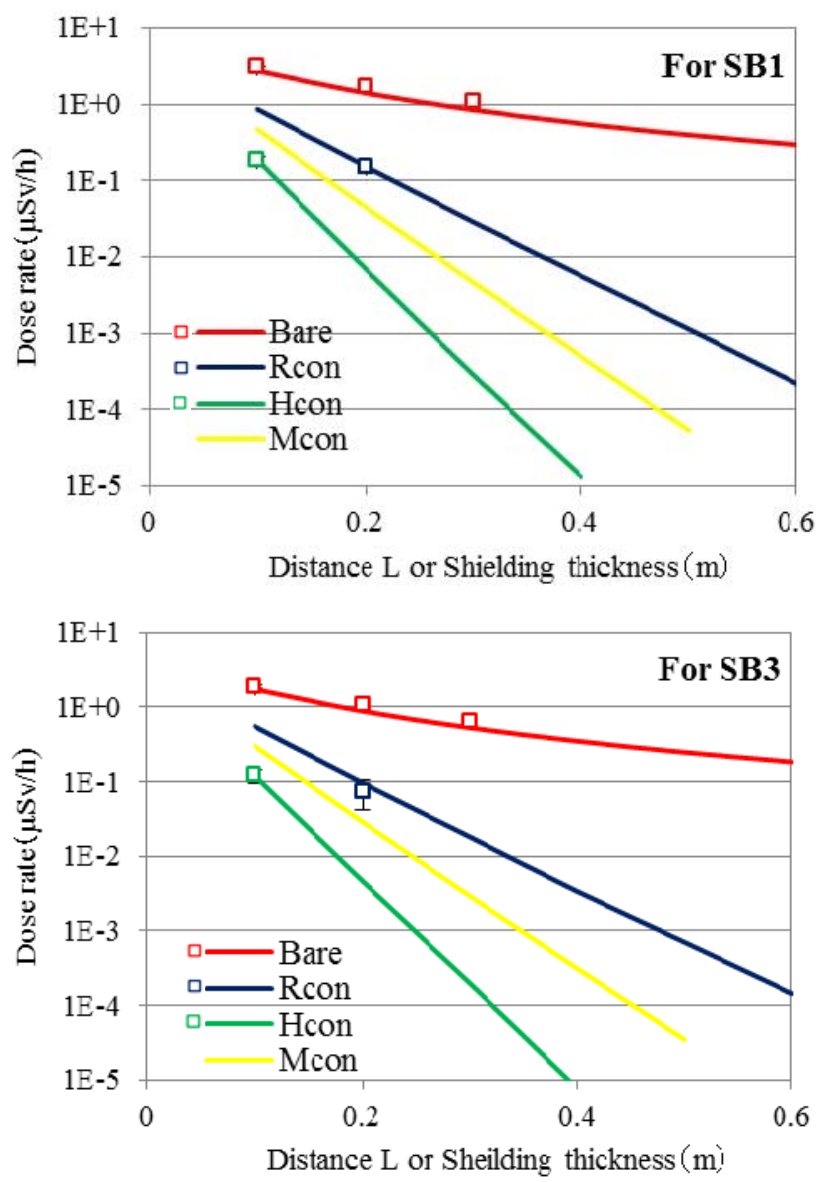

Figure 3. Attenuation profiles of dose rates due to the contaminated soil blocks as a function of distance $L$ for BARE and as a function of concrete shielding thickness of the pods for Rcon, Hcon and Mcon.
Table 3. C/E values of dose rates at the distances $\mathrm{L}$ from the soil block surfaces without pods (BARE) and with the concrete pods of Rcon ( $\mathrm{t}=0.2 \mathrm{~m})$ or Hcon $(\mathrm{t}=0.1 \mathrm{~m})$.

\begin{tabular}{|c|c|c|c|c|c|c|c|}
\hline \multirow{2}{*}{$\begin{array}{c}\mathrm{L} \\
(\mathrm{m})\end{array}$} & \multicolumn{3}{|c|}{ SB1 } & \multirow{2}{*}{$\begin{array}{l}\text { SB2 } \\
\text { Bare }\end{array}$} & \multicolumn{3}{|c|}{ SB3 } \\
\hline & Bare & Rcon & Hcon & & Bare & Rcon & Hcon \\
\hline 0.05 & - & - & - & 1.07 & - & - & - \\
\hline 0.1 & 0.88 & - & 1.02 & 0.98 & 0.93 & - & 1.02 \\
\hline 0.15 & - & - & - & 0.95 & - & - & - \\
\hline 0.2 & 0.83 & 1.01 & 0.75 & - & 0.84 & 1.30 & 1.06 \\
\hline 0.3 & 0.80 & 0.99 & 0.86 & - & 0.83 & 1.09 & - \\
\hline
\end{tabular}

(BARE) and with the concrete pods of Rcon $(\mathrm{t}=0.2 \mathrm{~m})$ or Hcon ( $\mathrm{t}=0.1 \mathrm{~m})$.

From the figure and the table, the simulated results gave quite good agreement with the measurements within the standard deviations of the measured data. Therefore, it can be said that the simulations in this work are reasonable accurate and this process can be applied to the optimization of shielding design of pods.

\section{Simulations for optimization of shielding design}

Additional simulations were performed to optimize shielding designs of the pods, changing shielding thickness, source activity, or concrete density. Cylindrical geometry of the simulation is similar as the last section, as shown in Figure 4. A volume source with two layers (SB3) was contained by a concrete pod (Rcon, Mcon, or Hcon) of diameter $\varphi$ and height $h$. The shielding thicknesses of side, up and bottom were defined as $t\left(=\left(\varphi-\varphi^{\prime}\right) / 2=\left(h-h^{\prime}\right) / 2\right)$. The volume source consisted of the Hsoil for inner soil block covered by the Lsoil for outer soil block, and the thickness of side, up and bottom for outer soil block were defined as $t_{s}$ ( $=$ $\left.\left(\varphi_{o s}-\varphi_{i s}\right) / 2=\left(h_{o s}-h_{i s}\right) / 2\right)$.

Dose rates per activity concentration were calculated while changing volume ratio of Hsoil $\left(\mathrm{R}^{\mathrm{V}}\right)$, which were

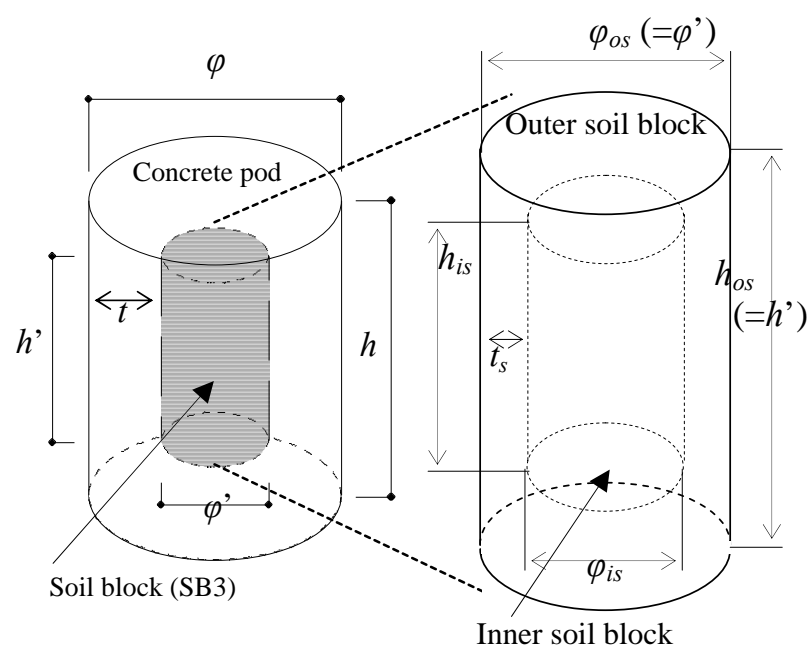

Figure 4. Soil block (SB3) covered by the concrete pod in left, and enlarged soil block part with two layers in right. 


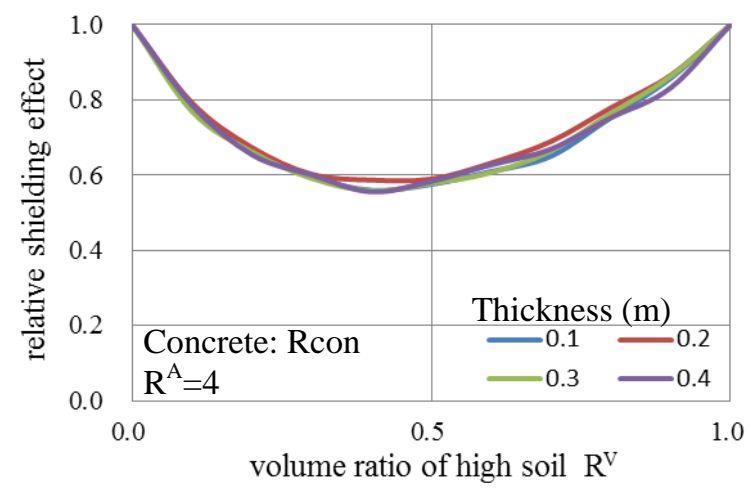

Figure 5. Calculated relative shielding effect by thickness.

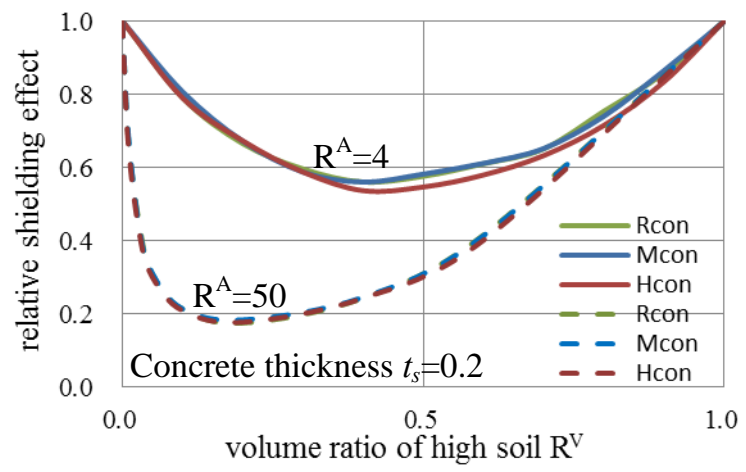

Figure 6. Calculated relative shielding effect by kind of concrete.

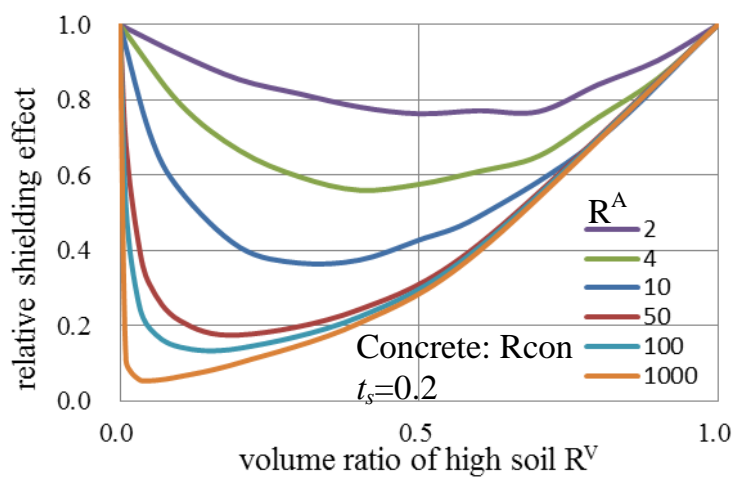

Figure 7. Calculated relative shielding effect by activity concentration ratio for Hsoil and Lsoil $\mathrm{R}^{\mathrm{A}}$.

defined by equation (1). Parameters of this calculation were, concrete thickness $(t=0.1-0.4 \mathrm{~m})$, ratio of activity concentration for Hsoil and Lsoil $\left(\mathrm{R}^{\mathrm{A}}\right)$ defined equation (2), and kinds of concrete related density of the concrete.

$$
\begin{gathered}
\mathrm{R}^{\mathrm{V}}=\text { V_Hsoil / (V_Hsoil+V_Lsoil) } \\
\text { V_Hsoil: volume of Hsoil, } \\
\text { V_Lsoil: volume of Lsoil }
\end{gathered}
$$

$$
\mathrm{R}^{\mathrm{A}}=\text { A_Hsoil / A_Lsoil }
$$

A_Hsoil: activity concentration of Hsoil

A_Lsoil: activity concentration of Lsoil

Shielding effects depending on the $\mathrm{R}^{\mathrm{V}}$ were simulated and the results were normalized to the values at $\mathrm{R}^{\mathrm{V}}=0$. Figures 5-7 show the thus obtained relative shielding effects as a function of $\mathrm{R}^{\mathrm{V}}$. Figure 5 indicates that relative shielding effect had less dependence of shielding thickness, and was minimum value when $\mathrm{R}^{\mathrm{V}}=0.4$. Figure 6 shows the relative shielding effect by changing kinds of concrete with different density in the case of $\mathrm{R}^{\mathrm{A}}=4$ and $\mathrm{R}^{\mathrm{A}}=50$. This figure indicates that relative shielding effect had less dependence of kinds of concrete. Figure 7 indicates that relative shielding effect had high dependence for soil activity concentration ratio, and was minimum values, $0.56,0.14,0.05$ when $\mathrm{R}^{\mathrm{V}}=0.4$ at $\mathrm{R}^{\mathrm{A}}=4, \mathrm{R}^{\mathrm{V}}=0.2$ at $\mathrm{R}^{\mathrm{A}}=100$, and $\mathrm{R}^{\mathrm{V}}=0.05$ at $\mathrm{R}^{\mathrm{A}}=1000$, respectively.

\section{Conclusion}

For the containment of the contaminated soils in Fukushima prefecture, two types of concrete shielding pods were developed, and were used for the demonstration of the effectiveness of shielding pods. Experimental works were performed using actual contaminated soil. Monte Carlo simulation was also carried out and clarified the validation of the simulation process in comparison with the experimental data. Using the same approach, another simulation was conducted to optimize the shielding design changing the volume ratio of two types of contamination soil in the shielding pods. The investigation above introduced to the high dependence of relative shielding effect to soil activity ratio and to the low dependences of thickness and density.

\section{References}

[1] S. M. J. Mortazavi, M. A. Mosleh-Shirazi, P. Roshan-Shomal, N. Raadpey and M. Baradaran-Ghahfarokhi, High-performance heavy concrete as a multi-purpose shield, Radiation Protection Dosimetry 142 (2010), pp.120-124.

[2] O. Gencel, W. Brostow, C. Ozel and M. Filiz, An investigation on the concrete properties containing colemanite, International Journal of Physical Sciences 5 (2010), pp.215-225.

[3] K. Kimura, M. Kinno, M. Nakamura, K. Nakajima, K. Aizawa and K. Suzuya, Boron-enriched mortar panel applied to the shielding wall of the spectrometer for reducing noise neutron at the BL14 in J-PARC, Genshiryoku Eye 55 (2009), pp.50-53. [in Japanese]

[4] K. Kimura, A. Hasegawa, K. Hayashi, M. Uematsu,T. Ogata, T. Tanosaki, R. Yoshino, M. Sato, M. Saito and M. Kinno, Development of low-activation design method for reduction of radioactive waste below clearance level, Proc. of the 16th Int. Conf. on Nuclear Engineering (ICONE16), Florida, USA, May 11-15, 2008, (2008), pp. 617-626. ISBN:0-7918-4841-0.

[5] X-5 Monte Carlo Team, MCNP-A General Monte Carlo N-Particle Transport Code Version 5, LA-UR-03-1987, Los Alamos National Laboratory, Los Alamos, USA, (2003). 
[6] H. G. Hughes, Information on the Photo Library MCPLIB02, LA-UR-08-539, Los Alamos National Laboratory, Los Alamos, USA, (1993).

[7] Atomic Energy Society of Japan, Radiation Dose
Conversion Coefficients for Radiation Shielding Calculations: 2010, AESJ-SC-R002, Tokyo, Japan, (2010). 